\title{
A metafunção interpessoal: um olhar sobre o artigo acadêmico de linguística
}

\author{
Interpersonal metafunction: a glimpse into the \\ research article genre
}

Cibele Gadelha Bernardino*

Universidade Estadual do Ceará

Fortaleza - Ceará / Brasil

RESUMO: O presente artigo tem por objetivo sistematizar reflexões acerca da metafunção interpessoal (HALLIDAY, 1994) no artigo acadêmico. Para tanto, realizamos a análise integral de um exemplar do artigo acadêmico da área de Linguística, estabelecendo um parâmetro entre a organização retórica do gênero e a utilização de recursos léxico-gramaticais relacionados à metafunção interpessoal. Os resultados parecem fornecer um breve olhar sobre como autores(as) podem construir seu posicionamento em um exemplar típico do gênero na área em questão.

PALAVRAS-CHAVE: metafunção interpessoal; modo; artigo acadêmico.

ABSTRACT: This article aims to systematize ideas about the interpersonal metafunction (HALLIDAY, 1994) in the academic article. Thus, we performed a comprehensive analysis of an example of an academic article from the Linguistic field, establishing a parameter between the rhetorical organization of this genre and the use of lexico-grammatical resources related to interpersonal metafunction. The results seem to provide a glimpse on how writers may construct their stance in a prototypical example of the genre from the field in study.

KEYWORDS: interpersonal metafunction; mode; academic article.

\section{Introdução}

Procurar compreender os mecanismos de um dado gênero do discurso é também movimentar-se na direção da compreensão das relações sociais associadas ao uso desse gênero. Entretanto, as questôes relacionadas aos mecanismos de estruturação e às diversas manifestações dos gêneros do discurso são complexas. Em função dessa complexidade, diversas pesquisas

$\overline{{ }^{*} \text { cibelegadelhab@gmail.com }}$ 
vêm sendo desenvolvidas desde a década de 1980. Observamos, porém, que ainda não existe um número significativo de pesquisas sobre a relação entre as escolhas léxico-gramaticais e a tipificação dos gêneros do discurso. Consideramos, pois, oportuno que observemos essas escolhas e a maneira como estão relacionadas à organização das diversas unidades que compõem o texto.

Uma análise de gêneros do discurso fundamentada em pressupostos da Gramática Sistêmico-Funcional parece-nos o caminho a ser trilhado em direção à caracterização de textos de modo a vinculá-los a determinado gênero.

Tendo em vista esse contexto teórico, neste artigo pretendemos responder à seguinte pergunta: de que maneira os elementos da metafunção interpessoal podem ser elementos caracterizadores do gênero artigo científico?

Para isso sistematizamos reflexôes acerca da metafunção interpessoal no gênero artigo acadêmico na área de Linguística. A partir do estudo de um exemplar, objetivamos descrever o funcionamento de elementos da metafunção interpessoal (Halliday, 1994) em todas as unidades retóricas que caracterizam o artigo científico experimental na referida área.

A fim de concretizarmos nosso propósito, teceremos, primeiramente, algumas considerações teóricas sobre a metafunção interpessoal. Em seguida, apresentaremos a metodologia que norteou o estudo, a análise e a discussão dos dados. Finalmente, apresentaremos nossas conclusões e as implicações desta pesquisa.

\section{Metafunção interpessoal: a gramática da interação}

Para Halliday (1994), o princípio básico da função interpessoal é que os falantes, no ato da interação, adotam para si um papel discursivo e sinalizam um papel complementar para seus interlocutores. Assim, ao realizar uma ordem, o falante se posiciona como alguém autorizado a ordenar e posiciona seu interlocutor como aquele que pode e deve efetivar o que foi ordenado. Dessa forma, a função interpessoal da linguagem desvela os papéis e as relações que os interlocutores constroem no ato das trocas interativas.

Halliday aponta dois tipos básicos de trocas que permeiam as interações: as trocas de bens e serviços e as trocas de informaçōes. Como procederemos à análise da função interpessoal em um exemplar do gênero artigo acadêmico, focalizaremos apenas a gramática da oração como troca de informação, ou seja, nosso olhar estará voltado para a troca de proposiçóes. 
A primeira questão a responder para discutir a relação entre a função interpessoal e os significados interpessoais construídos na interação é: que estruturas do sistema linguístico são preferencialmente utilizadas pelos falantes para a construção dessa relação?

Antes, porém, de respondermos a tal questão, consideramos pertinente para efeito metodológico estabelecer as diferenças entre as variadas nuanças do termo MODO encontradas no referencial teórico de M. A. K. Halliday.

Nesse construto teórico, a análise do Sistema de Modo da Língua utiliza o mesmo termo MODO em três níveis distintos:

- Modo como tipo de função discursiva das interações, neste artigo identificado como MODO1;

- Modo como estrutura central da oração na qual estão os constituintes léxico-gramaticais dos significados interpessoais, que passaremos a identificar como MODO2;

- Modo como parte da estrutura interna do MODO2, constituída por sujeito, finito e adjuntos modais, o qual denominaremos de MODO3.

Essa numeração é utilizada apenas para facilitar a leitura deste texto, não implicando nenhuma apreciação de valor acerca dos conceitos apresentados. Procuramos visualizar melhor as relações entre os termos a partir do esquema abaixo:

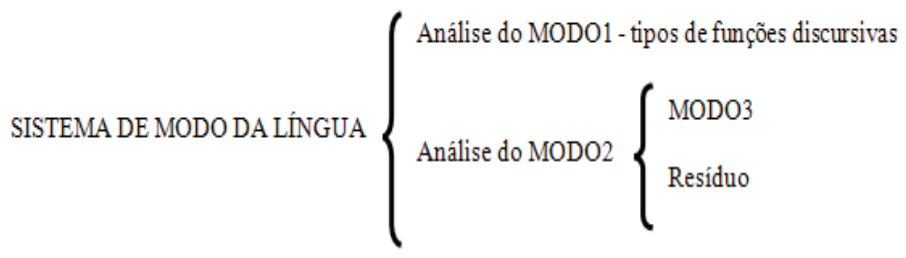

Retomando a questão acima proposta, como Martin (1997) aponta, é na estrutura dos elementos do MODO1 da gramática que o viés negociável da interação se revela com mais nitidez. Cabe, então, perguntar quais os constituintes relevantes para a descrição da estrutura do MODO1 da oração e em que diferentes configurações eles podem ocorrer?

Para Halliday (1994), os quatro tipos básicos de trocas interativas são declarar, questionar, oferecer e comandar. O ponto inicial das interações se 
dá por meio da escolha de uma dessas funções e sua realização através de estruturas gramaticais tipicamente escolhidas para codificá-las.

O passo seguinte da análise é observar de forma mais verticalizada a estrutura dessas orações e para fazer isto é necessário analisar o MODO2 aqui tomado como a estrutura central da oração na qual estão os constituintes léxico-gramaticais dos significados interpessoais. Do ponto de vista interpessoal, Halliday (1994) nos diz que a oração está dividida em MODO3 e RESÍDUO, sendo o MODO3 constituído por sujeito, partícula verbal de finito e adjuntos de modo e o RESÍDUO por predicador, complementos e adjuntos circunstanciais.

Antes de partirmos para a descrição de cada um desses constituintes, gostaríamos de chamar a atenção para as reflexôes propostas por Thompson (2002), para quem os significados interpessoais não estão exclusivamente ligados a constituintes específicos, mas se expandem à totalidade da oração. Para efeito metodológico, é importante considerar o sistema de modo como o centro da análise interpessoal, não esquecendo, porém, que estes significados podem ser reforçados e expandidos em outras estruturas da oração, ou seja, os significados interpessoais tendem a estar em torno do MODO2, mas não estão confinados a ele.

Passaremos, agora, ao tratamento dos constituintes do MODO3 e do RESÍDUO. Para tanto, tomaremos os conceitos e as descrições apontados por Halliday (1994) e estabeleceremos um diálogo com Eggins (1994), Martin (1997) e Thompson (2002).

Como já apontamos, o MODO3 é constituído por sujeito, finito e adjuntos modais. Halliday (1994) chama constantemente a atenção para a compreensão de que na estrutura do $\mathrm{MODO} 3$, o sujeito não deve ser tomado apenas como uma categoria gramatical cuja função predominante é a sintática. Antes, o sujeito deve ser tomado como um constituinte que imprime uma importante nuança semântica à significação da oração. Em proposiçōes, por exemplo, podemos caracterizar o significado do sujeito em termos de que elemento do significado interpessoal o falante põe em questão, ou seja, o sujeito é o elemento em relação ao qual o ouvinte pode construir afirmações, negações, questionamentos etc. Como nos diz Thompson (2002), o sujeito expressa a entidade que o falante deseja tornar responsável pela validade da proposição.

Quanto ao finito, Halliday (1994) nos diz que é o constituinte do MODO3 que tem a função de localizar a proposição no tempo (presente, 
passado, futuro), tornando-a algo sobre o que se pode comentar. Para Thompson (2002), a função do finito é orientar o ouvinte em direção ao tipo de validade que está sendo chamado para a proposição, relacionando-a ao aqui e ao agora da realidade do evento de fala e/ou relacionando-a à atitude do falante.

Eggins (1994), tomando Halliday (1985a) como referência apresenta dois operadores verbais do finito: os operadores de tempo e os operadores modais. Os primeiros ancoram a proposição à noção de tempo se presente, passado ou futuro. Os segundos ancoram a proposição não por referência ao tempo, mas por referência à modalidade, ou seja, são elementos do finito que expressam o julgamento do falante sobre as possibilidades ou obrigaçōes envolvidas no que é dito. Assim, a proposição torna-se alvo de comentário por ser apresentada como provável/improvável; desejável/indesejável; possível ou não. É importante considerar, ainda, que o finito também carrega a noção semântica de polaridade.

Por fim, podemos considerar, ainda, na estrutura do MODO3, os adjuntos modais. Para Halliday (1994), o adjunto é o elemento que não tem o potencial de ser sujeito e que é tipicamente realizado por um grupo adverbial ou uma frase preposicional. Halliday (1994) apresenta três classes de adjuntos: os adjuntos modais, os circunstanciais e os adjuntos textuais.

Os adjuntos modais são aqueles mais intimamente associados ao sistema de modo, imprimindo significados de polaridade, modalidade, temporalidade e modo. Ao analisarmos os adjuntos de polaridade e modalidade, percebemos que, além de considerarmos a proposição como algo que pode ser negado ou afirmado (polaridade), é fundamental considerar que entre os extremos da polaridade há uma gradação de níveis de certeza e/ou de usualidade que deve ser observada. Segundo Eggins (1994), são a essas escolhas intermediárias que associamos o termo modalização. A modalização é uma parte da gramática geral da área da modalidade. Portanto, quando a modalidade é usada para argumentar sobre a probabilidade ou a frequência das proposições, estamos nos referindo à modalização. Por outro lado, quando a modalidade é utilizada para argumentar sobre a obrigação ou a inclinação para a realização de propostas em trocas de bens e serviços, estamos nos referindo à modulação.

O outro tipo de adjunto modal apresentado por Halliday (1994) são os adjuntos de temporalidade subdivididos em dois tipos: os adjuntos de tempo propriamente dito (ainda que, até agora, já, uma vez que) e os adjuntos de 
tipicidade (ocasionalmente, geralmente, regularmente, na maior parte das vezes).

Por fim, Halliday (1994) nos apresenta os adjuntos de modo como aqueles que expressam significados de obviedade (de fato, obviamente, claramente), intensidade (somente, meramente, de fato, sempre) e grau (muito, escassamente, totalmente, completamente, quase).

Cabe ainda focalizarmos os chamados adjuntos de comentário. Para Halliday (1994), a diferença entre o adjunto de comentário e o adjunto de modo propriamente dito é que o primeiro expressa a atitude do falante em relação à proposição como um todo e não apenas aos elementos do MODO3. No entanto, por expressarem atitude e ou avaliação, estes adjuntos são considerados por Halliday (1994) e por Thompson (2002) como uma categoria dos adjuntos modais.

Quanto aos adjuntos circunstanciais, Halliday (1994) nos diz que adicionam conteúdo experiencial à oração por expressarem alguma circunstância relacionada ao processo oracional. São, portanto, vinculados aos significados experienciais mais do que aos interpessoais, motivo pelo qual estão posicionados fora do MODO3, fazendo parte do RESÍDUO. Por fim, a última classe de adjuntos apresentada por Halliday (1994) trata dos adjuntos conjuntivos. Estes adjuntos têm caráter textual e não modal. Sua função é estabelecer relações entre partes do texto, realizando uma função semântica de expansão da escrita.

Passemos, agora, ao tratamento do resíduo na estrutura do MODO2. Como já apontamos, o Resíduo é composto por predicador, complemento e adjuntos circunstanciais.

Eggins (1994) lembra que o Resíduo é a parte da estrutura do MODO2 de menor relevância para os comentários, podendo, pois, ser elipsado em respostas no diálogo. O predicador é a parte da estrutura verbal da oração que guarda a noção de processo, que adiciona a noção de tempo secundário e que especifica a voz verbal, se passiva ou ativa. É importante ressaltar que em estruturas verbais simples as noções de finito e predicador estarão fundidas. O complemento, segundo Halliday (1994) e Thompson (2002), é o elemento do resíduo tipicamente realizado por um grupo nominal que poderia ter sido escolhido como sujeito, mas não foi. Martin (1997) também afirma que o complemento tem o status de sujeito potencial.

Assim, a ordenação típica do resíduo é dada por predicador seguido de complemento, seguido de adjunto. 
Como podemos perceber, ao utilizarmos a linguagem para interagir, realizamos uma série de escolhas que estão vinculadas intimamente ao Sistema de Modo da Língua que, por sua vez, responde às necessidades interacionais dos falantes. Dessa forma, o referido Sistema constrói um terreno de trocas e negociações entre papéis e identidades, e institui dimensōes interpessoais que revelam níveis de poder, solidariedade, intimidade, julgamentos e atitudes dos falantes um em relação ao outro.

Essas consideraçōes nos mostram quão produtivo é o campo de investigação que envolve o estudo da estrutura do sistema de modo e da modalidade da língua, particularmente se associado aos padróes contextuais de registro e gênero. Aliás, percebemos que há uma considerável lacuna e, consequentemente, um enorme campo para pesquisa, na relação entre os padrôes de caracterização genérica e os padrões de constituição do sistema de modo e modalidade. Cremos que o estabelecimento dessa relação será um campo favorável para perceber como, nos gêneros discursivos, os sujeitos sociais se posicionam, constroem relações de poder, constituem identidades frente às suas comunidades discursivas e para fora delas. É, pois, partindo dessa expectativa, que tentaremos estabelecer este vínculo no ponto que segue, afunilando nossas reflexôes para o tratamento do gênero Artigo Experimental de Linguística.

\section{Metodologia}

O material analisado é composto por um artigo experimental da área de Letras e Artes, subárea de Linguística, coletado no site http://www.scielo. br. O artigo está vinculado aos estudos sobre Fonologia da Língua Portuguesa.

Vale salientar que denominamos artigo experimental (AE), com base em Swales (2004), aquele artigo que apresenta como objetivo central a análise de dados de quaisquer natureza e, portanto, apresenta, necessariamente, a unidade retórica de Análise e Discussão dos Dados.

A análise do exemplar de artigo experimental investigado nesta pesquisa tem como objetivos:

- Mapear e categorizar os elementos da metafunção interpessoal encontrados no artigo analisado;

- Evidenciar semelhanças e diferenças do comportamento da metafunção interpessoal nas diversas unidades retóricas do referido corpus; 
- Analisar as implicações do comportamento da metafunção interpessoal no corpus deste trabalho para a caracterização do gênero artigo científico, em pesquisas futuras.

\section{a. Os procedimentos de análise}

Este estudo está fundamentado nos pressupostos da Gramática Sistêmica Funcional de M. A. K. Halliday (1994) em diálogo com os estudos de Eggins (1994) Martin (1997) e Thompson (2002).

- Marcação manual dos elementos da metafunção interpessoal no artigo, a saber: tipos de sujeito, finito e adjuntos modais;

- Categorização e tabulação dos dados observados;

- Análise das ocorrências de cada categoria de dados (de cada elemento da metafunção interpessoal) dentro de uma mesma unidade retórica;

- Análise das ocorrências de cada elemento da metafunção interpessoal em relação à totalidade das unidades retóricas do artigo.

Na próxima seção, observaremos de que maneira a metafunção interpessoal encontra-se presente em um artigo científico experimental da área de Linguística e como essa função poderia auxiliar na caracterização do gênero artigo científico.

\section{Análise e discussão dos dados}

Como já esclarecemos na introdução, a análise aqui apresentada tem como objetivo perceber como os elementos dos significados interpessoais da linguagem se apresentam em um exemplar do gênero artigo experimental de Linguística. Assim, esta é uma análise exploratória que poderá revelar possíveis indicadores sobre o padrão de posicionamento e avaliação do(a) pesquisador(a)-autor(a) ao produzir exemplares desse gênero. A análise foi realizada a partir de um levantamento detalhado dos seguintes elementos constitutivos dos significados interpessoais segundo Halliday (1994): tipos de funções discursivas associadas à análise do $\mathrm{MODO}^{1}$; sujeito, finito (noções temporal e modal) e adjuntos modais associados à análise do MODO2 e

${ }^{1}$ A denominação em MODO1, MODO2 e MODO3 é de nossa autoria. 
do MODO3. Para efeito da organização da análise e com o objetivo de sistematizar os dados, auxiliando, assim, o leitor a percorrer conosco este caminho, apresentamos os resultados a partir de cada um dos elementos anteriormente apontados.

É importante lembrar que tivemos como objetivo específico verificar o comportamento desses elementos em cada uma das unidades retóricas típicas do gênero. Passemos então à análise.

\section{a. O MODO1: análise do modo das orações}

O primeiro passo para a análise foi caracterizar o tipo de troca predominante no artigo, se uma troca de informaçôes ou se troca de bens e serviços (HALLIDAY, 1994). Por se tratar de texto escrito cuja interação entre os interlocutores se faz, predominantemente, por vias verbais sem contato face a face, verificamos que o tipo de troca predominante é a troca de informações expressa principalmente pelo modo declarativo.

O segundo passo foi estabelecer a diferença entre as unidades de análise com as quais iríamos trabalhar. Buscamos em Halliday (1994) a distinção entre sentença e oração e verificamos que, na escrita, os sinais de pontuação (! / ? / "” / ( ) / , / ;) assinalam o significado de uma unidade ou seu status no texto. Eles não são primariamente sinais de fronteira entre sentenças, apesar de que alguns tendem a ocorrer em posições particulares da sentença, como os sinais de ! e ? que geralmente aparecem no final. Por outro lado, os sinais $(, / ; /: /-)$ marcam algum tipo de subsentença, alguma unidade que é intermediária entre a sentença e a palavra. Assim, a sentença pode ser interpretada como uma oração complexa por apresentar uma oração junto a outras que a modificam. Então, na estrutura hierárquica entre os constituintes gramaticais (sentença, oração, grupo ou frase, palavra e morfema), o termo sentença deve ser substituído por oração complexa, considerada como o nível imediatamente superior à oração. $\mathrm{O}$ termo sentença fica, pois, restrito à parte do texto escrito que finaliza com algum sinal de pontuação. Sentença é então uma unidade ortográfica e não gramatical.

Tomamos a decisão de trabalhar inicialmente com a sentença ortográfica para uma primeira impressão acerca do comportamento do MODO1 no texto e somente depois focalizar a análise sobre os modos $2 \mathrm{e}$ 3. Para este segundo momento, tomamos como unidade de análise a oração como troca, expressa pela estrutura do MODO2 (sujeito, finito predicador, complemento, adjunto). 
Nosso primeiro passo, após a definição das unidades mínimas de análise, foi dividir o texto em sentenças ortográficas e verificar a realização do MODO1, ou seja, qual a predominância dos tipos de funções discursivas. Chegamos, então, às seguintes tabelas ${ }^{2}$ do MODO1:

\section{TABELA M1a}

Quantificação com base no total de modos em cada unidade retórica

\begin{tabular}{|l|c|c|c|c|c|c|}
\hline Tipos de modos & MDA & MDN & MIP & MIA & MI & ME \\
Movimentos retóricos & & & & & & \\
\hline Introdução & $100 \%$ & - & - & - & - & - \\
\hline Revisão de Literatura & $88,23 \%$ & $9,80 \%$ & - & $1,96 \%$ & - & - \\
\hline Análise & $88,37 \%$ & $11,62 \%$ & - & - & - & - \\
\hline Considerações Finais & $88 \%$ & $8 \%$ & - & $4 \%$ & - & - \\
\hline
\end{tabular}

Tabela de nossa autoria

\section{TABELA M1b}

Quantificação com base no total de cada tipo de modo em todo o texto

\begin{tabular}{|l|c|c|c|c|c|c|}
\hline Tipos de modos & MDA & MDN & MIP & MIA & MI & ME \\
Movimentos retóricos & & & & & & \\
\hline Introdução & $7,7 \%$ & - & - & - & - & - \\
\hline Revisão de Literatura & $39,82 \%$ & $41,66 \%$ & - & $50 \%$ & - & - \\
\hline Análise & $33,62 \%$ & $41,66 \%$ & - & - & - & - \\
\hline Considerações Finais & $19,46 \%$ & $16,66 \%$ & - & $50 \%$ & - & - \\
\hline
\end{tabular}

Tabela de nossa autoria

Em primeiro lugar, é importante explicar que elaboramos dois quadros quantitativos para cada uma das unidades retóricas do artigo científico. $\mathrm{O}$ primeiro, tabela do tipo $a$, apresenta a ocorrência dos elementos analisados dentro da própria unidade retórica, o que nos possibilita comparar, nos quadros acima, por exemplo, os tipos e as frequências dos modos típicos das orações que ocorreram em cada uma das unidades separadamente.

${ }^{2}$ As siglas das TAB. M1a e M1b: MDA - Modo Declarativo Afirmativo; MDN - Modo Declarativo Negativo; MIP - Modo Interrogativo Polar; MIA - Modo Interrogativo Aberto com partícula WH; MI - Modo Imperativo; ME - Modo Exclamativo. 
Assim, a leitura da tabela deve ser realizada horizontalmente. O segundo tipo de tabela (tabela do tipo $b$ ) compara as ocorrências dos elementos entre as unidades retóricas. Nesta tabela, o que é isolado são os elementos léxico-gramaticais e não as unidades retóricas e, portanto, a leitura deve ser realizada verticalmente. Feitos estes esclarecimentos metodológicos, voltemos à análise.

Como podemos perceber, a TABELA M1a nos mostra a predominância do Modo Declarativo Afirmativo, tanto em cada um dos movimentos retóricos como na totalidade do artigo. Este resultado corrobora a indicação de que o tipo de troca predominante em artigos é a troca de informaçôes. Percebemos, ainda, que a unidade retórica Introdução somente apresentou orações do tipo MDA. O artigo em questão utiliza os seguintes movimentos retóricos para construir sua introdução:

- Apresentação do território de pesquisa;

- Apresentação do objetivo da pesquisa;

- Anúncio de alguns resultados;

- Indicação da estrutura do artigo.

Os movimentos retóricos utilizados pela autora explicam o porquê da predominância do modo declarativo afirmativo, uma vez que apenas apresentam a pesquisa sem preocupação em dialogar, neste momento do texto, com outros pesquisadores-autores, diminuindo, assim, a provável ocorrência de declarativas negativas ou de interrogativas.

Quanto à Revisão de Literatura, percebemos, além das declarativas afirmativas, a presença de declarativas negativas e interrogativas abertas (ver TAB. M1a). Aliás, é válido ressaltar que as declarativas negativas revelaram a mesma ocorrência também na unidade retórica de Análise (ver TAB. M1b). Parece-nos que a presença destes tipos de modos das oraçóes nestas unidades apresenta relação com o viés dialógico impresso em seus objetivos. Senão vejamos. Segundo Motta-Roth (2002), a unidade retórica Revisão de Literatura tem como objetivo central situar a pesquisa em um campo teórico e para tanto realiza entre outros movimentos retóricos os de citar pesquisas prévias, contra-argumentar pesquisas prévias e indicar lacunas em pesquisas prévias. Como podemos perceber, estes movimentos retóricos colocam o(a) pesquisador(a)-autor(a) em posição de interação. Muitas vezes, em posição de discordância frente aos resultados, ao referencial teórico ou 
ainda, à metodologia de outras pesquisas do campo (uso do modo declarativo negativo), ou na posição de quem põe em questão outras pesquisas (uso do modo interrogativo) ou mais frequentemente na posição de quem corrobora com outras pesquisas (uso do modo declarativo afirmativo).

Quanto às funções da unidade retórica de Análise, percebemos além da predominância do modo declarativo afirmativo, como já foi dito, a presença dos modos declarativo negativo e interrogativo aberto (ver TAB. M1a). Em relação ao primeiro modo, pensamos que sua maior frequência na unidade tem relação com o movimento retórico Declaração dos Resultados (MOTTAROTH, 2002, p. 79), que se mostra predominantemente descritivo, o que lhe imprime uma caracterização mais objetiva. Quanto aos modos declarativo negativo e interrogativo aberto, acreditamos que mantêm relação com os movimentos retóricos Avaliação da Descoberta, Comparação da Descoberta com a Literatura e, principalmente, com o movimento de Conclusão no qual, segundo Motta-Roth (2002), o(a) pesquisador(a)-autor(a) demonstra como seus resultados concordam ou contrastam com pesquisas prévias, assumindo, assim, uma postura de diálogo com outros pesquisadores-autores.

A unidade retórica Consideraçôes Finais também apresentou a predominância de frases declarativas afirmativas com as quais relacionamos o objetivo de apresentar resumidamente os resultados e as conclusões da pesquisa. A segunda maior frequência foi do modo declarativo negativo seguido pelo modo interrogativo aberto (ver TAB. M1a).

Em resumo, o exemplar do gênero apresentou predominância do modo declarativo afirmativo, seguido pelo declarativo negativo e com maior distância pelo interrogativo aberto. Constatamos, ainda, a ausência dos modos imperativo, interrogativo polar e exclamativo.

A ausência do modo imperativo parece ter relação com o tipo de troca predominante, posto que este modo é mais apropriado às trocas de bens e serviços (HALLIDAY, 1994). Quanto à predominância das interrogativas abertas em detrimento das interrogativas polares, pode estar associada à consideração de que o modo interrogativo em textos acadêmicos parece ter mais uma função retórica de organização textual do que a função discursiva de perguntar. E é o que percebemos em nosso exemplar de análise. Desta forma, as interrogativas abertas são sobremaneira mais eficazes, uma vez que funcionam retoricamente para conduzir o fluxo textual, posto que ao questionar sobre um elemento $\mathrm{X}$, lançam este elemento como provável tema e/ou sujeito das proposições seguintes, promovendo, assim, a continuidade 
textual. Já a ausência do modo exclamativo nos parece o outro lado da moeda do padrão de predominância do modo declarativo, ou seja, a ausência de exclamativas assim como a predominância de declarativas nos mostram uma ênfase no conteúdo, apontando para um texto no qual os fenômenos, os dados, os conceitos parecem falar por si, camuflando o papel do(a) pesquisador(a)-autor(a) como agente da elaboração textual e portanto da interpretação dos fenômenos, dos dados. Este padrão é o que perceberemos nas próximas seçōes da análise.

O terceiro passo da análise foi observar os elementos do MODO2. Ao final da análise, percebemos que os elementos que se mostraram relevantes foram os elementos da estrutura do MODO3, principalmente o sujeito, a noção de finito e os adjuntos modais. Esses foram os constituintes do MODO3 que nos pareceram mais relevantes para a caracterização do artigo cientifico experimental. Procederemos ao restante da análise, observando um a um esses elementos e seus comportamentos nas unidades retóricas do gênero.

\section{b. A análise do MODO3: o sujeito da metafunção interpessoal}

Como já esclarecemos, a noção teórica de sujeito dentro da função interpessoal é fundamental para o reconhecimento do elemento sobre o qual a proposição está ancorada, ou nos termos de Halliday (1994), de que elemento do significado interpessoal o falante põe em questão. Assim, o sujeito é o elemento em relação ao qual o interlocutor pode concordar ou discordar, construir afirmaçōes, negaçōes ou questionamentos. É, portanto, o elo interativo entre os interlocutores.

Em relação ao gênero artigo cientifico, consideramos que a noção de sujeito traz, ainda, uma importante informação sobre a fonte responsável pelos enunciados do texto. A descrição e a análise dos elementos escolhidos como sujeitos do ponto de vista interpessoal mostram, em grande medida, o quanto o(a) autor(a) se revela como fonte de suas proposiçóes ou o quanto se oculta ao escolher para posição de sujeito outros elementos que não o uso da primeira pessoa do discurso. Em nossa análise, percebemos que os pesquisadores utilizaram diferentes recursos linguísticos para construção do sujeito. Como não encontramos na gramática sistêmica desdobramentos para as categorizações deste elemento, apresentamos uma categorização que deu conta das principais ocorrências no texto analisado. Essas ocorrências foram: 
- $S 1$ - sujeito que está na esfera do conteúdo do que é falado, marcando o "sobre o que se fala". Ex: $O$ acento é uma propriedade relacional (p. 69).

- S2 - sujeito manifesto por meio de plural majestático elíptico. Ex: Nas duas primeiras seçôes definimos o que entendemos por choque acentua [...] (p. 68).

- S3 - sujeito manifesto por meio do pronome de primeira pessoa do plural indicando a conexão entre autor e leitor (Nós - autor + leitor). Ex: No entanto, o que podemos observar é que nem sempre [...] (p. 71).

- S4 - sujeito coisificado - uso de termos como trabalho, hipótese substituindo a fonte da autoria e assumindo, portanto, o papel semântico de participante do processo em questão. Ex: Pesquisas em fonologia prosódica discutem uma série de fenômenos fonológicos [...] (p.69).

- S5 - sujeito que indica discurso reportado. Ex: Frota e Abousalah (1997) argumentam que [...] (p. 69).

- S6 - sujeito indeterminado. Ex: Em ambas as análises, perde-se a distinção [...] (p. 72).

Vejamos como esta categorização se apresentou em nosso exemplar do gênero em análise:

\section{TABELA 1a}

Quantificação com base no total de tipos de sujeito em cada unidade retórica

\begin{tabular}{|l|c|c|c|c|c|}
\hline Tipos de Sujeito & S1 & S2 & S3 & S4 & S5 \\
Movimentos Retóricos & & & & & \\
\hline Introdução & $27,27 \%$ & $31,81 \%$ & - & $36,36 \%$ & - \\
\hline Revisão da Literatura & $68,69 \%$ & $6,08 \%$ & $3,47 \%$ & $4,34 \%$ & $8,69 \%$ \\
\hline Análise/discussão & $71,09 \%$ & $5,46 \%$ & $6,25 \%$ & $0,78 \%$ & $3,90 \%$ \\
\hline Considerações Finais & $70,37 \%$ & $6,17 \%$ & - & $14,81 \%$ & $1,23 \%$ \\
\hline
\end{tabular}

Tabela de nossa autoria 


\section{TABELA $1 b$}

Quantificação com base no total de cada um dos tipos de sujeito em todo o texto

\begin{tabular}{|l|c|c|c|c|c|}
\hline Tipos de Sujeito & S1 & S2 & S3 & S4 & S5 \\
Movimentos Retóricos & & & & & \\
\hline Introdução & $2,58 \%$ & $36,84 \%$ & - & $29,62 \%$ & - \\
\hline Revisão da Literatura & $34,05 \%$ & $36,84 \%$ & $33,33 \%$ & $18,51 \%$ & $62,5 \%$ \\
\hline Análise/discussão & $39,22 \%$ & $36,84 \%$ & $66,66 \%$ & $3,70 \%$ & $31,25 \%$ \\
\hline Considerações Finais & $24,56 \%$ & $26,31 \%$ & - & $44,44 \%$ & $6,25 \%$ \\
\hline
\end{tabular}

Tabela de nossa autoria

Como já explicamos em relação à análise do MODO1, a análise dos constituintes da função interpessoal para apontar elementos de caracterização do gênero foi realizada por meio do cruzamento dos dados especificados nas tabelas dos tipos $a$ e $b$. Em $a$, comparamos os constituintes dentro de uma mesma unidade retórica e em $b$ os comparamos entre as diferentes unidades.

Observando a TABELA 1a, podemos perceber a predominância do sujeito do tipo S1 nas unidades retóricas, com exceção da Introdução, que apresenta a predominância de $\mathrm{S} 4$. Acreditamos que esta predominância corrobora o que já apontamos acerca do modo declarativo, ou seja, predominância de um conteúdo que se apresenta por si mesmo ao leitor, apagando a fonte real do discurso.

Aqui é interessante refletir sobre dois aspectos. Primeiro, a presença deste tipo de sujeito parece ter íntima relação com o gênero, uma vez que a troca de informações agregada aos objetivos de discutir experimentos ou fazer levantamentos de pesquisas prévias é a tônica em artigos científicos. É claro que, além do aspecto descritivo do artigo cientifico, é importante considerar que, ao descrever o estudo, o(a) autor(a) também pode avaliar resultados, argumentar e construir conclusōes, mas a forma como isso vai se manifestar nos textos produzidos vai depender de fatores como, por exemplo, os diferentes parâmetros de apropriação do gênero por diferentes áreas de estudo.

$\mathrm{O}$ segundo aspecto acerca da predominância de $\mathrm{S} 1$ e do modo declarativo é que, quando o conteúdo fala por si, a possibilidade de ocorrência de elementos modalizadores diminui, colocando estas proposiçóes em uma situação difícil de questionar. Como nos diz Eggins (1994), quanto mais dizemos que algo é certo ou provável, menos certo e provável ele é. Se estamos certos sobre algo, não usamos modalizadores, simplesmente afirmamos. 
Quanto à não predominância de S1 na Introdução, acreditamos que tem íntima relação com os propósitos desta unidade retórica. Isto é, na Introdução o objetivo central não é descrever conteúdo, mas apresentar o tema, os objetivos e a relevância do trabalho. Vale refletir, ainda, sobre as predominâncias de S4 e S2 em detrimento de outras possibilidades que poderiam ter sido escolhidas como o uso da $1^{\text {a }}$ pessoa do singular ou a indeterminação do sujeito. A opção por $\mathrm{S} 4$ nos mostra uma busca de apagamento total da fonte do discurso, como podemos perceber em construçóes do tipo Este trabalho trata da relação entre sintaxe e fonologia [...] (p. 68) ou Este trabalho se organiza da seguinte maneira [...] (p. 68). Este apagamento é realizado por meio do recurso da metáfora gramatical (HALLIDAY, 1994) no nível dos significados experienciais, ou seja, os processos tratar de organizar que seriam prototipicamente acompanhados por participantes que carregam traço semântico [+humano] passam a ter como participantes elementos com traços [+inanimado], [-humano], transferindo a agência do(a) autor(a) para o próprio exemplar do gênero em expressões como este artigo, este trabalho que passam a ser apontadas como a fonte da proposição. Por outro lado, o uso de S2 revela uma opção por dissolver a voz da autora nas diversas vozes da comunidade acadêmica. Isso nos indica que se, por um lado, a pesquisadora-autora busca apagar sua posição como fonte do discurso, por outro, alguns recursos utilizados para esse fim acabam por trazer à tona na superfície do texto esta mesma posição. Essa explicação nos é apresentada por Coracini (1991, p. 104) nos seguintes termos:

Como seria de se esperar em vista das convençōes científicas, o sujeito enunciador assume, o tempo todo, a postura de um observador distante do objeto observado, como que provando, com sua ausência explicita, a ausência do sujeito-pesquisador na etapa da investigação cientifica. Entretanto, não raro se observa que, ao mesmo tempo em que se ausentam, as instâncias enunciativas se revelam sub-repticiamente através dos mesmos recursos linguísticos.

Passemos, agora, para as ocorrências do sujeito na unidade retórica de Revisão da Literatura. Nesta unidade, como já apontamos e analisamos, o tipo de sujeito predominante é S1. Concentraremo-nos, então, no tratamento da segunda maior ocorrência - o sujeito do tipo S5 que indica discurso reportado. Mais uma vez, consideramos que esta ocorrência responde aos propósitos da unidade retórica posto que é nesta unidade que o(a) pesquisador(a)-autor(a) situa sua pesquisa dentro de um campo maior 
e para tanto cita pesquisas prévias, dialogando com outros pesquisadoresautores. Isso, aliás, é visível se observarmos a TABELA 1 b que ao comparar as unidades retóricas, revela a predominância de S5 como característica da Revisão de Literatura. Esta é, pois, a unidade retórica na qual o aspecto dialógico da produção científica se revela com mais clareza.

Outro aspecto importante é que o uso de $S 5$ necessariamente exige do(a) pesquisador(a) a construção de um posicionamento que pode se dar de forma mais ou menos explícita. Desta maneira, ao utilizar o discurso reportado, a autora cita para concordar, utilizar como argumento de autoridade, discordar, revelar lacunas etc.

Por fim, vale ressaltar que os sujeitos dos tipos S2, S3 e S4 também fizeram parte da Revisão de Literatura, mas assumiram menor frequência em relação a $S 1 \mathrm{e}$ S5 e menor relevância em relação aos usos desses três sujeitos nas demais unidades.

Observando a unidade retórica Análise, percebemos a predominância de $S 1$, tanto dentro da própria unidade (ver TAB.1a) quanto em relação às demais unidades retóricas (ver TAB.1b). O sujeito do tipo S3 correspondeu à segunda maior ocorrência e houve pequena incidência de $S 4$.

Ao olharmos a TABELA $1 \mathrm{~b}$, percebemos a grande predominância do sujeito do tipo S3 na unidade retórica de Análise. Aliás, esse tipo de sujeito somente foi utilizado nas unidades de Revisão de Literatura e Análise, sendo mais recorrente nesta última. Se tomarmos em consideração que é na unidade de Análise que o(a) pesquisador(a)-autor(a) apresenta, discute e argumenta a favor de seus achados, poderemos associar a escolha de S3 à busca da adesão do leitor para os posicionamentos da autora. $\mathrm{O}$ uso do pronome nós do tipo S3, ao mesmo tempo em que deixa emergir no texto a fonte discursiva, engaja o leitor na teia argumentativa construída pela autora, assumindo, pois, um importante papel interativo.

Quanto à pequena ocorrência de S4, acreditamos que corrobora a nossa apreciação de que a unidade retórica de Análise é, em nosso exemplar, aquela na qual a pesquisadora-autora mais manifesta seu posicionamento como fonte do discurso, uma vez que é nesta unidade que está a predominância de S3 e S2. Considerando que S4 é a opção dentre os sujeitos que mais oculta a autoria, não surpreende sua reduzida ocorrência na Análise.

Vale chamar atenção, ainda, para a ocorrência de S5 na Análise como recurso por meio do qual a pesquisadora-autora busca apoio para a validade de seus argumentos nas vozes de autoridades da área, ou por outro lado, cita estas vozes para, ao apresentar uma lacuna ou um contra-argumento, construir tal validade. 
Por fim, a unidade retórica Consideraçōes Finais apresentou o sujeito coisificado (S4) como segunda maior ocorrência dentre os demais sujeitos construídos dentro dessa unidade (ver TAB.1a) e a primeira ocorrência se compararmos a frequência desse tipo de sujeito nas demais unidades (ver TAB.1b). Isso se deve ao uso de termos como conclusão, dados, resultados, assumindo a agência das proposiçôes por meio de metáfora gramatical, como já foi explicado no uso de S4 na unidade retórica Introdução.

É válido comentar, ainda, sobre a pequena ocorrência de $S 5$ nas Consideraçôes Finais, tanto em relação aos demais sujeitos (ver TAB.1a) quanto na comparação entre as unidades (ver TAB.1b), apontando que nesta unidade tal como na Introdução que não apresenta S5, a pesquisadora-autora já não mais sente a necessidade de recorrer ao discurso reportado.

Para finalizar, apresentamos abaixo as características gerais da construção dos significados interpessoais por meio do sujeito no exemplar do gênero artigo científico experimental aqui analisado:

- Predominância da busca de ocultamento da fonte do discurso, sendo que esse ocultamento manifesta ocorrências distintas nas unidades retóricas;

- Na Introdução o ocultamento da pesquisadora-autora se faz, preponderantemente, por meio do sujeito coisificado (S4) e do plural majestático (S2);

- Nas demais unidades retóricas, o ocultamento se faz por episódio da predominância de sujeito na esfera do conteúdo (S1), seguido por S5 (sujeito que apresenta discurso reportado), na Revisão de literatura, sujeito S3 (Nós - autor + leitor) na Análise e S4 (sujeito coisificado) nas Consideraçôes Finais;

- A unidade retórica de Análise é aquela em que a pesquisadora -autora se manifesta mais como fonte das proposiçôes, pois é a unidade que tem predominância de S3 e S2;

- As Consideraçôes Finais é a unidade retórica em que a pesquisadora-autora menos se revela, haja vista a predominância de $\$ 4$, a ausência de S3 e o menor índice de S2.

\section{c. Análise do MODO3: a noção de finito temporal}

Antes de iniciarmos a análise sobre o padrão modo-temporal do exemplar analisado, cabe fazermos algumas consideraçôes sobre a noção de 
finito (HALLIDAY, 1994), a partir das realizações em língua portuguesa. Em primeiro lugar, devemos apontar que o modo e o tempo verbal em português são noções desinenciais. Assim, a noção do finito se faz, em geral, na própria estrutura do predicador e, nos casos de expressões verbais, na estrutura do verbo auxiliar. Outra consideração importante é que em português, diferentemente do inglês, a noção de polaridade não está no finito, mas nos adjuntos modais de polaridade que, via de regra, estão posicionados junto ao finito na organização sintagmática da oração. Feitos estes esclarecimentos, passemos à análise e discussão dos dados apresentados nas TABELAS 2a e 2b.

\section{TABELA 2a}

Quantificação com base no total das dimensões temporais de finitos em cada unidade retórica

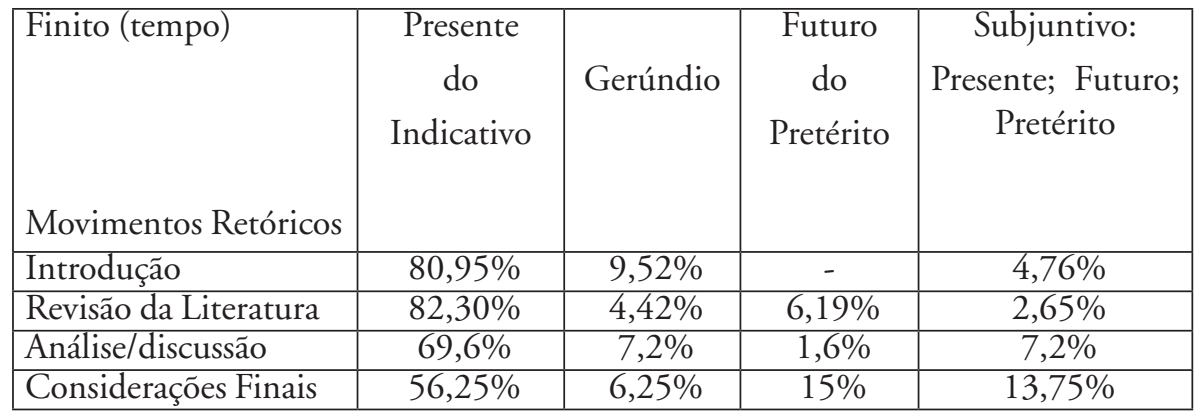

Tabela de nossa autoria

\section{TABELA $2 b$}

Quantificação com base no total de cada uma das dimensōes temporais de finitos em todo o texto

\begin{tabular}{|l|c|c|c|c|}
\hline Finito (tempo) & $\begin{array}{c}\text { Presente } \\
\text { do } \\
\text { Indicativo }\end{array}$ & Gerúndio & $\begin{array}{c}\text { Futuro } \\
\text { do } \\
\text { Pretérito }\end{array}$ & $\begin{array}{c}\text { Subjuntivo: } \\
\text { Presente; Futuro; } \\
\text { Pretérito }\end{array}$ \\
Movimentos Retóricos & $7,05 \%$ & $9,52 \%$ & - & $4,16 \%$ \\
\hline Introdução & $38,58 \%$ & $23,80 \%$ & $33,33 \%$ & $12,5 \%$ \\
\hline Revisão da Literatura & $36,09 \%$ & $42,85 \%$ & $9,52 \%$ & $37,5 \%$ \\
\hline Análise/discussão & $18,67 \%$ & $23,80 \%$ & $57,14 \%$ & $45,83 \%$ \\
\hline Consideraçôes Finais & & & \\
\hline
\end{tabular}

Tabela de nossa autoria 
A primeira constatação a que chegamos, após um levantamento detalhado de todos os tempos verbais do exemplar analisado, foi quanto aos modos e tempos verbais relevantes para a análise dos significados interpessoais na caracterização do gênero em questão. Chegamos, então, às seguintes ocorrências: presente do indicativo, futuro do pretérito, os tempos do subjuntivo e o gerúndio.

Ao olharmos a TABELA 2a, percebemos claramente a predominância do presente do indicativo em cada uma das unidades retóricas, com maior incidência na Revisão de Literatura (ver TAB. 2b). Tal predominância parece ter relação com a consideração de que o presente do indicativo é utilizado para, entre outros objetivos, enunciar fatos cuja ocorrência está atrelada ao momento da enunciação, o chamado presente momentâneo (CUNHA e CINTRA, 1985) ou para indicar ações ou estados permanentes, por exemplo, assertivas científicas e artigos de lei, o chamado presente durativo (CUNHA e CINTRA, 1985).

Como podemos perceber, as duas realizações do presente do indicativo apontadas acima estão em acordo com os resultados que já apresentamos, nos tópicos anteriores, sobre a predominância do sujeito do tipo S1 e do modo declarativo que põem a ênfase do texto nas declaraçôes sobre conteúdos.

Coracini (1991), ao analisar artigos científicos, constata que o presente do indicativo é o tempo verbal que se presta a enunciar comentários, bem como apresentações de pesquisa, resultados, discussões e conclusões, posicionados no momento da enunciação. Esta escolha do(a) pesquisador(a)autor(a) busca relacionar tempo real com tempo do enunciado, imprimindo um viés mais objetivo às declaraçôes. Além disso, o presente do indicativo transforma o texto em uma série de asserçôes que, à primeira vista, parecem difíceis de questionar, haja vista a realização do presente durativo.

Quanto ao gerúndio, cuja predominância entre as unidades retóricas deu-se na Análise (ver TAB. 2b), observamos duas dimensões. Primeiro, a dimensão aspectual a partir da qual o gerúndio presta-se, predominantemente, à construção do aspecto cursivo progressivo (NEVES, 2000), ou seja, apresenta o desenvolvimento do processo em progressão. Segundo, a dimensão do gerúndio como recurso para ocultamento do sujeito.

O uso do gerúndio para apontar aspecto cursivo progressivo esteve sempre associado, em nosso exemplar de análise, ao padrão $S 1$ do sujeito. 
Isto é, o gerúndio, cursivo progressivo, prestou-se, prioritariamente, às proposições cujos sujeitos eram o próprio conteúdo. Como podemos visualizar nos exemplos: Construçóes envolvendo tópico em PB [...] (p. 77) e [...] temos um PRO preenchendo a posição de objeto (p. 78).

Quanto à segunda dimensão, que esteve em construções como Explorando esta hipótese, investigaremos nas próximas seçôes [...] (p. 74) ou Assumindo que esta análise está correta [...] (p. 75), percebe-se o ocultamento do sujeito na oração. Acreditamos que é por não comportar desinências de pessoa-número e, portanto, não apontar a pessoa do discurso vinculada ao processo, que o gerúndio presta-se a este ocultamento do sujeito. Em algumas ocorrências, a fonte discursiva pôde ser recuperada textualmente como em Na seção 4, analisamos os dados, envolvendo categorias sintáticas vazias [...] (p. 68). Em outros casos, somente o conhecimento do leitor sobre a presença de um autor por trás do texto é capaz de indicar tal fonte.

O futuro do pretérito ocorreu preferencialmente na unidade Considerações Finais e não ocorreu na Introdução (ver TAB. 2b). É importante notar, ainda, que o futuro do pretérito foi a segunda maior ocorrência tanto nas Consideraçôes Finais quanto na Revisão de Literatura (ver TAB. 2a).

Acreditamos que a importância do futuro do pretérito para a caracterização do posicionamento da pesquisadora-autora nestas unidades retóricas deve-se à capacidade que este tempo verbal tem de exprimir a noção de suavização de uma afirmação ou a noção de avaliação de informações obtidas por canais intermediários (VILELA e KOCH, 2001). Assim, nas Consideraçôes Finais onde a pesquisadora-autora apresenta suas conclusōes, o futuro do pretérito presta-se à função de suavizar as declarações da pesquisadora-autora, posicionando-a como alguém que não acredita em conclusões definitivas e absolutas. Já na Revisão de Literatura onde há uma constante referência aos achados e teorias de outros, o futuro do pretérito presta-se prioritariamente, a apresentar informações obtidas por canais intermediários, expressando o baixo grau de comprometimento da pesquisadora-autora com relação a estas informações.

Por fim, observemos os tempos do subjuntivo que em nosso exemplar mostraram-se mais recorrentes nas unidades retóricas Consideraçôes Finais e Análise, respectivamente com 45,83\% e 37,5\% (ver TAB. 2b), considerando, ainda, que na Análise este modo verbal representou juntamente com o gerúndio a segunda maior ocorrência e nas Consideraçôes Finais a terceira maior ocorrência (ver TAB. 2a). 
Para Vilela e Koch (2001), a semântica do modo subjuntivo pode ser definida em oposição à do indicativo, ou seja, é o modo do não-realizado ou ainda não realizado. É o modo que, privilegiadamente, exprime subjetividade. Perini (2000) nos diz que o subjuntivo é o modo que expressa atitude de incerteza, dúvida ou desejo do falante frente ao conteúdo do enunciado. Tomando estas consideraçôes como válidas para justificar e explicar a predominância dos tempos do subjuntivo nas duas unidades anteriormente apontadas em comparação à sua incipiente ocorrência na Introdução e na Revisão de Literatura, acreditamos que o subjuntivo está, no exemplar em análise, particularmente associado à relativização dos resultados e das conclusões construídas pela autora no texto.

Para fechar este tópico, podemos pontuar que:

- O presente do indicativo (presente momentâneo e presente durativo) é o tempo verbal predominante em todas as unidades retóricas do artigo;

- É na unidade Consideraçôes Finais que a pesquisadora-autora mais relativiza os conteúdos expressos nas proposições, pois é a unidade na qual o futuro do pretérito e o modo subjuntivo são predominantes;

- É na Introdução que a autora menos se posiciona por meio do finito, pois esta unidade não apresenta futuro do pretérito e apresenta a menor ocorrência do modo subjuntivo.

\section{d. Análise do MODO3: a noção de finito modal}

Neste tópico observaremos o finito em seu viés modalizador e mais uma vez é importante esclarecer que as TABELAS $3 \mathrm{a}$ e $3 \mathrm{~b}$ mostram as formas do finito que foram mais recorrentes, e, portanto, mais relevantes para a caracterização do posicionamento da pesquisadoraautora. Percebemos, então, que a noção modal do finito foi expressa, prioritariamente, pelos modalizadores poder, poder ser e poder estar, construindo significados de possibilidade epistêmica (NEVES, 2000), seguidos pelos modalizadores dever e dever ser construindo significados de necessidade deôntica (NEVES, 2000). 
TABELA 3a

Quantificação com base no total de verbos de modalização em cada unidade retórica

\begin{tabular}{|l|c|c|}
\hline Modalização & $\begin{array}{c}\text { (de possibilidade) } \\
\text { poder; poder ser/estar }\end{array}$ & $\begin{array}{c}\text { (de obrigação) } \\
\text { dever; dever ser }\end{array}$ \\
\hline Introdução & $100 \%$ & - \\
\hline Revisão da Literatura & $58,33 \%$ & $20,83 \%$ \\
\hline Análise/ discussão & $82,35 \%$ & $17,64 \%$ \\
\hline Considerações Finais & $44,44 \%$ & $33,33 \%$ \\
\hline
\end{tabular}

Tabela de nossa autoria

TABELA $3 b$

Quantificação com base no total de cada um dos tipos de verbos de modalização em todo o texto

\begin{tabular}{|l|c|c|}
\hline Modalização & $\begin{array}{c}\text { (de possibilidade) } \\
\text { poder; poder ser/estar }\end{array}$ & $\begin{array}{c}\text { (de obrigação) } \\
\text { dever; dever ser }\end{array}$ \\
\hline Introdução & $7,14 \%$ & - \\
\hline Revisão da Literatura & $50 \%$ & $45,45 \%$ \\
\hline Análise/ discussão & $50 \%$ & $27,27 \%$ \\
\hline Considerações Finais & $14,28 \%$ & $27,27 \%$ \\
\hline
\end{tabular}

Tabela de nossa autoria

Se observarmos a TABELA 3a, verificaremos que a modalização de possibilidade epistêmica é predominante em todas as unidades retóricas, perfazendo, inclusive, $100 \%$ da modalização verbal na Introdução. Por outro lado, ao observarmos a TABELA 3 b, a concentração desse tipo de modalização está equitativamente dividida entre as unidades Revisão de Literatura e Análise, enquanto a modalização de necessidade deôntica (obrigação) é predominante na Revisão de Literatura.

Os dados anteriores nos mostram que a unidade retórica Introdução é aquela em que a modalização verbal tem menor incidência (ver TAB. 3b). Percebemos também resultados que apontam, na introdução, a forte presença do sujeito coisificado, a predominância do presente do indicativo em detrimento do subjuntivo e a ausência do futuro do pretérito. Isso indica a Introdução como a unidade retórica mais opaca quanto ao posicionamento da autoria.

Quanto à predominância da modalização de possibilidade epistêmica nas unidades de Revisão de Literatura e Análise, acreditamos que na 
primeira destas unidades, esta modalização associa-se, a exemplo do que se mostrou com o futuro do pretérito, à construção de significados de avaliação de informações obtidas por canais intermediários, revelando um comprometimento apenas parcial da pesquisadora-autora frente às proposiçôes enunciadas. $\mathrm{Na}$ segunda unidade, também similarmente ao futuro do pretérito, estes verbos modalizadores parecem construir significados de suavização sobre as declarações da pesquisadora-autora, imprimindo aos resultados da análise uma nuança de relativização.

Por último, é válido chamar atenção para a predominância da necessidade deôntica (obrigação) na unidade retórica Revisão de Literatura. Esta recorrência parece estar relacionada a duas manifestações. Uma delas é a ocorrência de proposições que se prestam a descrever procedimentos como em A sentença em (2a) deve ser mapeada como em (2b) [...] (p. 70). A outra, a ocorrência de proposiçôes sobre categorizações, dados e conceitos já bem estabelecidos na área de conhecimento, como em [...] observamos que a estrutura (13b), correspondente a (12b), deve ter entre o verbo e o advérbio uma categoria sintática foneticamente vazia [...] (p. 74).

Vejamos agora como a modalização se apresenta por meio dos adjuntos modais.

\section{e. Análise do MODO3: os adjuntos modais}

Cada adjunto foi categorizado segundo sua ocorrência na unidade retórica (TAB. 4a) e segundo sua ocorrência em relação ao texto como um todo (TAB. 4b), conforme veremos, a seguir.

\section{TABELA 4a}

Quantificação com base no total de adjuntos em cada unidade retórica

\begin{tabular}{|c|c|c|c|c|c|}
\hline Adjuntos & & & & & \\
\hline $\begin{array}{l}\text { Movimentos } \\
\text { Retóricos }\end{array}$ & Polaridade & Probabilidade & Usualidade & Intensidade* & Obviedade \\
\hline Introdução & $50 \%$ & $50 \%$ & - & - & - \\
\hline $\begin{array}{l}\text { Revisão da } \\
\text { Literatura }\end{array}$ & $73,33 \%$ & $20 \%$ & $13,33 \%$ & - & - \\
\hline Análise & $66,66 \%$ & $14,81 \%$ & $3,70 \%$ & $7,40 \%$ & $7,40 \%$ \\
\hline $\begin{array}{l}\text { Considerações } \\
\text { Finais }\end{array}$ & $64,28 \%$ & $14,28 \%$ & $7,14 \%$ & $7,14 \%$ & - \\
\hline
\end{tabular}

Tabela de nossa autoria 
TABELA 4b

Quantificação com base no total de cada um dos tipos de adjuntos em todo o texto

\begin{tabular}{|l|c|c|c|c|c|}
\hline Adjuntos & Polaridade & Probabilidade & Usualidade & Intensidade* & Obviedade \\
$\begin{array}{l}\text { Movimentos } \\
\text { Retóricos }\end{array}$ & $2,56 \%$ & $10 \%$ & - & - & - \\
\hline Introdução & $28,20 \%$ & $30 \%$ & $50 \%$ & - & - \\
\hline $\begin{array}{l}\text { Revisão da } \\
\text { Literatura }\end{array}$ & $46,15 \%$ & $40 \%$ & $25 \%$ & $66,66 \%$ & $100 \%$ \\
\hline Análise & $23,07 \%$ & $20 \%$ & $25 \%$ & $33,33 \%$ & - \\
\hline Conclusão & & & & & \\
\hline
\end{tabular}

Tabela de nossa autoria

Com base nos dados apresentados nas TABELAS 4a e 4b, observamos que a Introdução é a unidade retórica que apresenta a menor ocorrência de adjuntos modais. Isto talvez seja explicado pelo fato de que, nesta unidade, a pesquisadoraautora apenas apresenta os objetivos e a organização do seu artigo.

Por outro lado, a Análise e a Conclusão são as unidades que apresentam o maior número de adjuntos modais. A Análise e a Conclusão apresentam um maior número de adjuntos de polaridade (ex. (p. 75): [...] não se aplicam [...]) e de probabilidade (ex. (p. 69): [...] isto é, só é possivel dizer [...]). $\mathrm{Na}$ Análise, que, em relação às demais unidades, apresenta o maior número de adjuntos de polaridade e probabilidade, a pesquisadora-autora discute seus dados e apresenta reflexões. $\mathrm{Na}$ Conclusão, a pesquisadora-autora apresenta considerações finais e implicações de sua pesquisa. Isto pode indicar uma maior necessidade de modalização do discurso.

$\mathrm{Na}$ Revisão da Literatura, na Análise e na Conclusão, percebemos maior ocorrência dos adjuntos de polaridade. Este dado está relacionado às ocorrências de orações no modo declarativo negativo e ao fato de, em português, os adjuntos de polaridade apresentarem-se junto ao finito. $\mathrm{O}$ adjunto de polaridade traz à cena do texto o diálogo com uma afirmação que é dada como pressuposta por meio de uma negação. Observamos, também, que nas unidades retóricas citadas neste parágrafo os adjuntos de probabilidade foram os que ocorreram com a segunda maior frequência. Isto está de acordo com os resultados já apresentados em relação ao tempo e ao modo do finito, indicando relativização sobre as proposições.

É possível observar que os adjuntos de usualidade (ex. (p. 71): [...] nem sempre o encontro de acentos [...].), obviedade (ex. (p. 75): [...] possam ser claramente 
identificadas.) e intensidade (ex. (p. 75): [...] são plenamente aceitáveis [...].) têm menor ocorrência no texto, parecendo apontar para um menor posicionamento avaliativo (julgamento de valor) da pesquisadora-autora. Isto pode estar relacionado à busca de objetividade que é característica do discurso científico.

O mapeamento vertical e horizontal dos dados apresentados ao longo desta seção - que cruza os dados das tabelas do tipo $a$ e $b$ - nos leva a caracterizar as unidades retóricas do ponto de vista da metafunção interpessoal da maneira apresentada na figura a seguir:

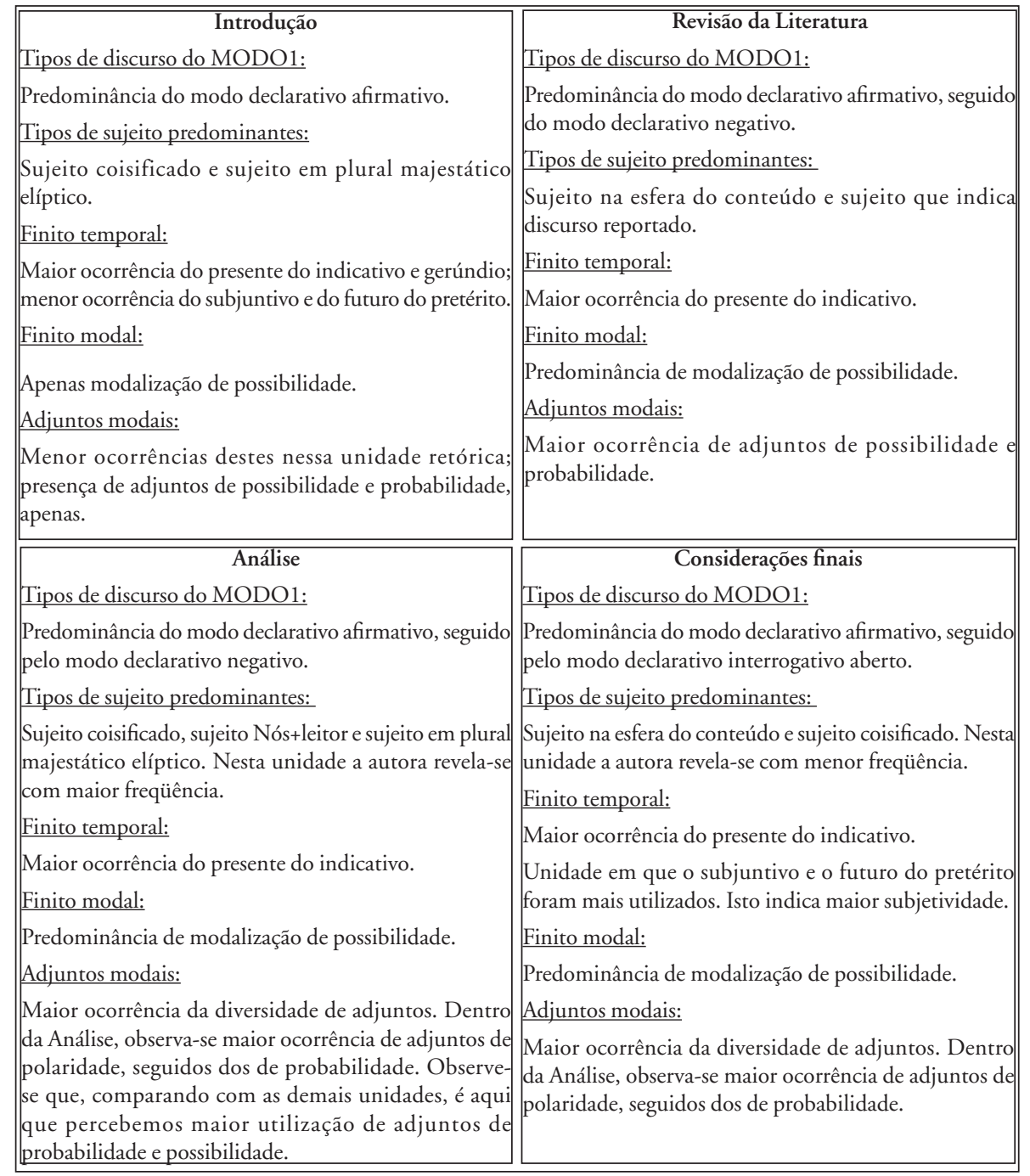

Figura de nossa autoria

FIGURA 1 - Caracterização dos significados interpessoais nas unidades retóricas 


\section{Considerações finais}

A análise aqui apresentada contribui, sobremaneira, para fornecer indicativos sobre como os(as) pesquisadores(as)-autores(as) da área disciplinar de Linguística constroem seus mecanismos de posicionamento e avaliação ao produzirem exemplares do gênero artigo científico. Certamente compreendemos que, dada a pequena dimensão do material de análise, estes indicadores funcionam, antes de tudo, como ponto de partida para outras pesquisas que pretendam realizar este tipo de investigação em um corpus de dimensão mais significativa.

\section{Referências}

CORACINI, M. J. Um fazer persuasivo: o discurso subjetivo da ciência. São Paulo: EDUC, 1991.

CUNHA, C.; CINTRA, L. Nova gramática do português contemporâneo. Rio de Janeiro: Editora Nova Fronteira, 1985.

EGGINS, S. An introduction systemic functional linguistics. London and New York: CONTINUUM, 1994.

HALLIDAY, M. A. K. The analysis of scientific texts in English and Chinese. In: HALLIDAY, M. A. K.; MARTIN, J. R. Writing science: literacy and discursive power. Great Britain: University of Pittsburgh Press, 1993. p. 124-132.

HALLIDAY, M. A. K.; MARTIN, J. R. Writing science: literacy and discursive power. Great Britain: University of Pittsburgh Press, 1993.

HALLIDAY, M. A. K. An introduction to functional grammar. Edward Arnold, 1994.

MARTIN, J. R. Factual writing: exploring and challenging social reality. HongKong: Oxford University Press, 1989.

MARTIN, J. R. Writing science: literacy and discursive power. Great Britain: University of Pittsburgh Press, p. 166-202, 1993.

MARTIN, J. R. Working with Functional Grammar. London: ARNOLD, 1997.

MARTIN, J. R.; ROTHERY, J. What a functional approach to the writing task can show teachers about 'good writing'. In: COUTURE, Barbara. (Ed.). Functional approaches to writing: research perspectives. Norwood: Ablex, p. 241-265, 1986.

MOTTA-ROTH, D. A construção social do gênero resenha acadêmica. In: MEURER, J. L.; MOTTA-ROTH, D. (Org.). Gêneros textuais e práticas discursivas: subsídios para o ensino da linguagem. Bauru: EDUSC, p. 77-116, 2002a.

MOTTA-ROTH, D. A importância do conceito de gêneros discursivos no ensino de redação acadêmica. In: Intercâmbio, v. 8, p. 119-128, 1999. 
MOTTA-ROTH, D. (Org.). Redação acadêmica: princípios básicos. Santa Maria: Universidade Federal de Santa Maria, Imprensa Universitária, 2002b.

MOTTA-ROTH, D.; HENDGES, G. R. Uma análise de gênero de resumos acadêmicos (abstracts) em Economia, Linguística, e Química. In: Revista do Centro de Letras e Artes - UFSM, v. 18, n. 1-2, p. 53-90, jan./dez. 1996.

NEVES, M. H. M. Gramática de usos do português. São Paulo: UNESP, 2000.

PERINI, M. A Gramática descritiva do português. São Paulo: Ática, 2000.

SWALES, J. Research genres: explorations and applications. Cambridge: Cambridge University Press, 2004.

THOMPSON, G. Introducing Functional Grammar. London: Arnold, 2002.

VILELA, M.; KOCH, I. V. Gramática da língua portuguesa. Coimbra: Almedina, 2001.

Data de submissão: 17/08/2014. Data de aprovação: 12/11/2014. 